\title{
Editorial: Clinical and Hemodynamic Performance of Aortic Endografts
}

\author{
Efstratios Georgakarakos* \\ Department of Vascular Surgery, Democritus University of Thrace, University Hospital of Alexandroupolis, Alexandroupolis, \\ Greece
}

Keywords: hemodynamics, endovascular therapy, aneurysm, bioengineering, endografts

\section{Editorial on the Research Topic}

\section{Clinical and Hemodynamic Performance of Aortic Endografts}

OPEN ACCESS

Edited by:

Stavros K. Kakkos,

University of Patras, Greece

Reviewed by:

Fragiska Sigala,

National and Kapodistrian University

of Athens, Greece

Efthymios Avgerinos,

University of Pittsburgh Medical

Center, United States

*Correspondence:

Efstratios Georgakarakos

efstratiosgeorg@gmail.com

Specialty section:

This article was submitted to

Vascular Surgery,

a section of the journal

Frontiers in Surgery

Received: 13 February 2018

Accepted: 01 June 2018

Published: 22 June 2018

Citation:

Georgakarakos E (2018) Editorial:

Clinical and Hemodynamic

Performance of Aortic Endografts.

Front. Front. Surg. 5:44.

doi: 10.3389/fsurg.2018.00044
Endovascular Aneurysm Repair (EVAR) is considered the treatment of choice in the majority of abdominal aortic aneurysms (AAA) since it is associated with low perioperative morbidity and mortality as well as a shortened hospital stay compared to open surgical repair $(1,2)$.

At first, classic endograft (EG) design was uniform and simple; it comprised a bifurcated configuration of fabric (either polutetrafluoroethylene of woven polyester) sewn with a self-expanding Nitinol endoskeleton (3). The latter ensured the central and distal sealing by means of stent oversizing whereas the central fixation was enhanced via hooks, pins, barbs, and anchors (4). Both hemodynamic and clinical performance of endografts are significantly affected by several geometric factors, the most important of which are the infrarenal neck angulation, diameter and shape, the curvature of EG, and the ratios of the proximal-to-distal diameters (Georgakarakos et al.) $(5,6)$.

According to the Human Aortic Anatomy Project, only 32\% of men and 12\% of women fulfill all 3 instructions for use (IFU) for the infrarenal neck (length, angulation, diameter) for AAA of 5-5.5 cm, whereas these percentages decrease significantly for AAA greater than 6$6.5 \mathrm{~cm}$ (7). Notably, EVAR outside-the-IFU is adapted by a significant percentage of physicians in real-world practice, putting those patients in significantly greater risk of developing type-I endoleak with consequent increased aneurysm-related mortality $(8,9)$. Therefore, EVAR evolution is characterized by significant modifications and developments in the design of aortic endografts in order to enhance the mechanical stability, practical applicability, and clinical endurance in the long term (Scaife et al.; Kontopodis et al.).

Interestingly, the need for minimally invasive repair of endovascular failures (i.e., avoiding the open repair or conversion) led to custom-made designs or EG hybrid solutions that combine components from different commercially available endografts (i.e., main-bodies/aortic cuffs/iliac limbs) with different biomechanical and structural properties (stress on metallic endoskeleton, strains in fabric) $(10,11)$. Notably, altered geometrical patterns of these new designs, such as reduced mainbody length (i.e., reduced mainbody-to-iliac limbs ratio) differentiate certain hemodynamic indices such as drag forces, shear stress or pressure distribution along the endograft $(12,13)$. Moreover, emerging endovascular technologies focusing on intrasac 
sealing rather that infrarenal fixation comprise a totally new research field, since the hemodynamic basis of mid- and longterm sealing are not fully understood (14). Interestingly, novel developments such as pivotal-FEVAR, low-profile endografts to overcome the stenosed and angulated iliac arteries burden as well as endoanchoring to treat migration and type-I endoleaks are worth mentioning innovations, the long-term efficiency of which has to be proven $(3,15)$. Lastly, the hemodynamic performance of parallel grafts used in complex repair techniques (chimneys,

\section{REFERENCES}

1. Powell JT, Sweeting MJ, Ulug P, Blankensteijn JD, Lederle FA, Becquemin JP, et al. Meta-analysis of individual-patient data from EVAR-1, DREAM, OVER and ACE trials comparing outcomes of endovascular or open repair for abdominal aortic aneurysm over 5 years. Br J Surg. (2017) 104:166-78. doi: 10.1002/bjs. 10430

2. Patel R, Sweeting MJ, Powell JT, Greenhalgh RM; EVAR trial investigators. Endovascular versus open repair of abdominal aortic aneurysm in 15years' follow-up of the UK endovascular aneurysm repair trial 1 (EVAR trial 1): a randomised controlled trial. Lancet (2016) 388:2366-74. doi: 10.1016/S0140-6736(16)31135-7

3. Schoretsanitis N, Georgakarakos E, Argyriou C, Ktenidis K, Georgiadis GS. A critical appraisal of endovascular stent-grafts in the management of abdominal aortic aneurysms. Radiol Med. (2017) 122:309-18. doi: 10.1007/s11547-017-0724-z

4. Melas N, Saratzis A, Saratzis N, Lazaridis J, Psaroulis D, Trygonis K, et al. Aortic and iliac fixation of seven endografts for abdominal-aortic aneurysm repair in an experimental model using human cadaveric aortas. Eur J Vasc Endovasc Surg. (2010) 40:429-35. doi: 10.1016/j.ejvs.2010.07.007

5. Georgakarakos E, Argyriou C, Schoretsanitis N, Ioannou CV, Kontopodis N, Morgan R, et al. Geometrical factors influencing the hemodynamic behavior of the AAA stent grafts: essentials for the clinician. Cardiovasc Intervent Radiol. (2014) 37:1420-9. doi: 10.1007/s00270-014-0927-9

6. Schuurmann RCL, van Noort K, Overeem SP, Ouriel K, Jordan WD Jr, Muhs BE, et al. Aortic curvature is a predictor of late type ia endoleak and migration after endovascular aneurysm repair. J Endovasc Ther. (2017) 24:411-7. doi: 10.1177/1526602817700378

7. Sweet MP, Fillinger MF, Morrison TM, Abel D. The influence of gender and aortic aneurysm size on eligibility for endovascular abdominal aortic aneurysm repair. J Vasc Surg. (2011) 54:931-7. doi: 10.1016/j.jvs.2011.02.054

8. Schanzer A, Greenberg RK, Hevelone N, Robinson WP, Eslami MH, Goldberg RJ, et al. Predictors of abdominal aortic aneurysm sac enlargement after endovascular repair. Circulation (2011) 123:2848-55. doi: 10.1161/CIRCULATIONAHA.110.014902

9. Antoniou GA, Georgiadis GS, Antoniou SA, Kuhan G, Murray D. A metaanalysis of outcomes of endovascular abdominal aortic aneurysm repair in snorkels, and fenestrated EVAR) remains to be investigated in order to gain information to aid the development of dedicated stent-graft types for improvement of the long-term results of the aforementioned techniques (Kandail et al.).

\section{AUTHOR CONTRIBUTIONS}

The author confirms being the sole contributor of this work and approved it for publication.

patients with hostile and friendly neck anatomy. J Vasc Surg. (2013) 57:527-38. doi: 10.1016/j.jvs.2012.09.050

10. Matsagkas MI, Kouvelos G, Spanos K, Athanasoulas A, Giannoukas A. Double fixation for abdominal aortic aneurysm repair using AFX body and Endurant proximal aortic cuff: mid-term results. Interact Cardiovasc Thorac Surg. (2017) 25:1-5. doi: 10.1093/icvts/ivx087

11. Demanget N, Duprey A, Badel P, Orgéas L, Avril S, Geindreau C, et al. Finite element analysis of the mechanical performances of 8 marketed aortic stent-grafts. J Endovasc Ther. (2013) 20:523-35. doi: 10.1583/12-4063.1

12. Georgakarakos E, Kratimenos T, Koutsoumpelis A, Georgiadis GS. The Bolton Treo endograft for treatment of abdominal aortic aneurysms: just another trimodular platform? Expert Rev Med Devices (2018) 15:5-14. doi: 10.1080/17434440.2018.1419864

13. Raptis A, Xenos M, Kouvelos G, Giannoukas A, Matsagkas M. Haemodynamic performance of AFX and Nellix endografts: a computational fluid dynamics study. Interact Cardiovasc Thorac Surg. (2018) 26:826-33. doi: $10.1093 /$ icvts/ivx414

14. Boersen JT, Groot Jebbink E, Versluis $\mathrm{M}$, Slump $\mathrm{CH}, \mathrm{Ku} \mathrm{DN}$, de Vries JP, et al. Flow and wall shear stress characterization after endovascular aneurysm repair and endovascular aneurysm sealing in an infrarenal aneurysm model. J Vasc Surg. (2017) 66:1844-53. doi: 10.1016/j.jvs.2016. 10.077

15. Georgakarakos E, Xenakis A, Bisdas T, Georgiadis GS, Schoretsanitis N, Antoniou GA, et al. The shear stess profile of the pivotal fenestrated endograft at the level of the renal branches: a computational study for complex aortic aneurysms. Vascular (2016) 24:368-77. doi: 10.1177/1708538115598726

Conflict of Interest Statement: The author declares that the research was conducted in the absence of any commercial or financial relationships that could be construed as a potential conflict of interest.

Copyright (C) 2018 Georgakarakos. This is an open-access article distributed under the terms of the Creative Commons Attribution License (CC BY). The use, distribution or reproduction in other forums is permitted, provided the original author(s) and the copyright owner are credited and that the original publication in this journal is cited, in accordance with accepted academic practice. No use, distribution or reproduction is permitted which does not comply with these terms. 